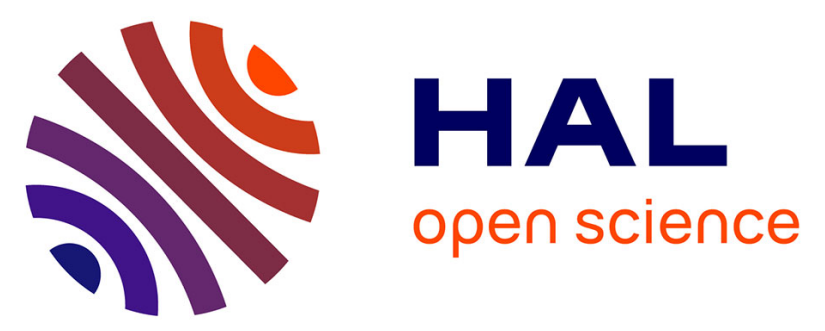

\title{
Muscle characteristics and meat quality traits are affected by divergent selection on residual feed intake in pigs
}

Louis L. Lefaucheur, Bénédicte Lebret, Patrick P. Ecolan, Isabelle Louveau, Marie M. Damon, Armelle Prunier, Yvon Y. Billon, Pierre P. Sellier, Hélène Gilbert

\section{To cite this version:}

Louis L. Lefaucheur, Bénédicte Lebret, Patrick P. Ecolan, Isabelle Louveau, Marie M. Damon, et al.. Muscle characteristics and meat quality traits are affected by divergent selection on residual feed intake in pigs. Journal of Animal Science, 2011, 89 (4), pp.996-1010. 10.2527/jas.2010-3493 . hal-01000532

\section{HAL Id: hal-01000532 \\ https://hal.science/hal-01000532}

Submitted on 29 May 2020

HAL is a multi-disciplinary open access archive for the deposit and dissemination of scientific research documents, whether they are published or not. The documents may come from teaching and research institutions in France or abroad, or from public or private research centers.
L'archive ouverte pluridisciplinaire HAL, est destinée au dépôt et à la diffusion de documents scientifiques de niveau recherche, publiés ou non, émanant des établissements d'enseignement et de recherche français ou étrangers, des laboratoires publics ou privés. 


\section{JOURNAL OF ANIMAL SCIENCE}

The Premier Journal and Leading Source of New Knowledge and Perspective in Animal Science

\section{Muscle characteristics and meat quality traits are affected by divergent selection on} residual feed intake in pigs

L. Lefaucheur, B. Lebret, P. Ecolan, I. Louveau, M. Damon, A. Prunier, Y. Billon, P. Sellier and H. Gilbert

J ANIM SCI 2011, 89:996-1010.

doi: 10.2527/jas.2010-3493 originally published online December 10, 2010

The online version of this article, along with updated information and services, is located on the World Wide Web at:

http://www.journalofanimalscience.org/content/89/4/996 


\title{
Muscle characteristics and meat quality traits are affected by divergent selection on residual feed intake in pigs ${ }^{1}$
}

\author{
L. Lefaucheur, ${ }^{* 2}$ B. Lebret, ${ }^{*}$ P. Ecolan, ${ }^{*}$ I. Louveau, ${ }^{*}$ M. Damon, ${ }^{*}$ A. Prunier, ${ }^{*}$ \\ Y. Billon, $\dagger$ P. Sellier, $\ddagger$ and H. Gilbert $\ddagger$
}

\begin{abstract}
*INRA, UMR1079 Systèmes d'Elevage, Nutrition Animale et Humaine, F-35590 Saint-Gilles, France;
$\nmid$ †NRA, UE967 Génétique Expérimentale en Productions Animales, F-17700 Surgères, France; and $\ddagger$ INRA, UMR1313 Génétique Animale et Biologie Intégrative, F-78352 Jouy-en-Josas, France
\end{abstract}

\begin{abstract}
Residual feed intake (RFI) is defined as the difference between the observed feed intake and that expected based on requirements for maintenance and production. A divergent selection was conducted during 4 generations in Large White male pigs to produce low and high RFI lines. The present study aims at determining the influence of this selection on biochemical and histological traits of skeletal muscle, and relating these changes to correlated effects on growth, carcass composition, and meat quality traits. At $8 \mathrm{~d}$ preslaughter, biopsies from the LM were taken in the fed state on 14 females from each RFI line fed ad libitum. Animals were slaughtered at $107.8 \pm 8.0 \mathrm{~kg}$ of $\mathrm{BW}$ without any previous fasting. Samples of LM, semimembranosus (SM), biceps femoris (BFM), and rhomboideus muscles were taken at both $30 \mathrm{~min}$ and $24 \mathrm{~h}$ postmortem. Myofiber typing was only assessed in LM. Low RFI pigs ("efficient") had leaner carcasses with greater muscle content $(P<0.001)$, less backfat thickness $(P<0.001)$, and less intramuscular fat content in all 4 muscles $(P$ $<0.01$ to $P=0.04$ ). Their greater muscle content was associated with hypertrophy of all fast-twitch fibers. Glycogen content in all glycolytic muscles (i.e., LM, $\mathrm{SM}$ and $\mathrm{BFM}$ ), was greater in low than high RFI pigs.
\end{abstract}

The greater accumulation of glycogen in LM of low RFI pigs was specifically located in the fast-twitch glycolytic IIBW fibers, which correspond to fibers containing IIb, IIb + IIx, or IIx myosin heavy chains. The difference in muscle glycogen content between RFI line pigs was more significant in the living animals $(P=0.0003)$ than at $30 \mathrm{~min}$ postmortem $(P=0.08)$. This was associated with a decreased ultimate $\mathrm{pH}(P=0.001)$, and greater lightness of color $(P=0.002)$ and drip loss $(P=0.04)$ in LM of low than high RFI line pigs, suggesting that selection for reduced RFI may impair some meat quality traits, such as water-holding capacity. Pigs from the low RFI line exhibited a greater $(P=0.02)$ percentage of IIBW fibers in LM and tended $(P<0.10)$ to have less lipid $\beta$-oxidative capacity in LM, SM, and BFM. In contrast, no difference $(P>0.10)$ between lines was found for citrate synthase and lactate dehydrogenase activities, mitochondrial activity, and expression of genes coding for uncoupling proteins 2 and 3. Differences between RFI pigs in plasma leptin, cortisol, and thyroid hormone concentrations are presented and discussed. In conclusion, selection for low RFI influenced muscle properties in a way favoring muscle mass, but likely impairing meat quality.

Key words: meat quality, muscle composition, muscle fiber type, residual feed intake, selection line, swine

(C)2011 American Society of Animal Science. All rights reserved.

J. Anim. Sci. 2011. 89:996-1010

doi:10.2527/jas.2010-3493

\section{INTRODUCTION}

Improving feed efficiency is a relevant way to reduce both the cost of pork production and the environmental impact of pig production. Residual feed intake (RFI)

\footnotetext{
${ }^{1}$ The study was supported by INRA (Institut National de la Recherche Agronomique, France). The authors gratefully acknowledge the staff of the INRA experimental farm, slaughterhouse, and laboratories involved in this study.

${ }^{2}$ Corresponding author: Louis.Lefaucheur@rennes.inra.fr

Received September 6, 2010.

Accepted December 2, 2010.
}

is defined as the difference between the observed feed intake and that expected on the basis of requirements for maintenance and growth (Kennedy et al., 1993). At INRA, a divergent selection experiment for RFI has been undertaken under ad libitum feeding conditions in Large White (LW) male pigs to produce a low ("efficient") and a high ("luxurious") RFI line (Gilbert et al., 2007). After 4 generations of selection, reducing RFI was genetically correlated with decreased carcass backfat thickness $\left(\mathrm{r}_{\mathrm{a}}=0.44 \pm 0.16\right)$ and increased lean meat content (LMC; $\left.\mathrm{r}_{\mathrm{a}}=-0.55 \pm 0.14\right)$. Interestingly, a correlated genetic response to selection was a decreased ultimate $\mathrm{pH}$ and an increased lightness in glycolytic 
muscles of pigs from the low vs. high RFI line, suggesting an impairment of some pork quality traits in the low RFI line. A recent review shows that multiple physiological processes are involved in interanimal variations in RFI, such as feed intake and digestion processes, metabolic utilization of feed, thermogenesis, physical activity, stress susceptibility, and health status (Herd and Arthur, 2009). Because skeletal muscle accounts for approximately $50 \%$ of body mass and about $25 \%$ of basal metabolic rate (Henriksson, 1990), changes in contractile and metabolic properties of skeletal muscle could explain some variation in RFI and correlated effects on muscle development and meat quality. The major objective of the current study was to compare biochemical and histological traits of skeletal muscle between low and high RFI pigs after 4 generations of divergent selection, and relate these changes to correlated effects on muscle growth, meat quality traits, and hormonal status of the animals. Different muscle sampling and myofiber typing technologies were evaluated to compare the 2 RFI lines.

\section{MATERIALS AND METHODS}

During the whole experiment, animals were raised in accordance with French legislation on animal experimentation. Pigs were slaughtered by electrical stunning and exsanguination in compliance with the current national French regulations applied in slaughterhouses.

\section{Animals and Experimental Design}

The selection experiment was conducted at INRA within the French LW breed as described previously in detail by Gilbert et al. (2007). All pigs were free of the RyR1 halothane-sensitive (n) and AMP-activated protein kinase (AMPK) $\gamma 3$ R225Q mutations (Fujii et al., 1991; Milan et al., 2000). Briefly, the phenotype for RFI was predicted from a selection index derived as a multiple regression of ADFI, ADG, backfat thickness, and metabolic BW at the phenotypic level. Divergent selection for RFI was conducted during 4 generations in noncastrated males recorded between 35 and $95 \mathrm{~kg}$ of BW, whereas random selection was performed on females, each dam being replaced randomly by 1 daughter. Eight to twelve animals per pen were offered ad libitum a pelleted diet based on cereals and soybean meal (10 MJ of NE/kg, $160 \mathrm{~g}$ of $\mathrm{CP} / \mathrm{kg}$, with at least $0.80 \mathrm{~g}$ of digestible Lys/MJ of NE). Feed intake of each candidate and some sibs was recorded in the INRA facilities in Rouillé (Poitou-Charentes, France) using a single-place electronic feeder ACEMA 64 (Pontivy, France) as described previously (Labroue et al., 1994). The estimated difference in RFI between the high and low lines after 4 generations was 0.72 phenotypic SD (i.e., $79 \mathrm{~g} / \mathrm{d}$ ). The present study involved 14 females from each line (from 5 different litters and 3 to 4 sires within lines) at similar final slaughter BW $(107.8 \pm 8.0$ $\mathrm{kg}$ ). Two series of animals from 2 pens ( 1 per line, 6 to
8 pigs) equipped with collective feeders and tested in 2 successive batches were transported from Rouillé to INRA experimental facilities in Saint-Gilles ( $4 \mathrm{~h}$ transport) at about $100 \mathrm{~kg}$ of $\mathrm{BW}$, without any mixing of pigs between pens. Genetic analyses using the REML methodology (Patterson and Thompson, 1971) applied to a multi-trait individual animal model (Gilbert et al., 2007) were carried out including the pedigree of generations 0 to 4 . In generation 4, differences of genetic values between the low and high RFI lines for the 27 animals involved in the present study were similar to those estimated between their contemporary groups. Thus, differences were 10.5 points for the selection index (compared with 12.8 points for the contemporary group), corresponding to $76.7 \mathrm{~g} / \mathrm{d}$ (compared with 93.0 $\mathrm{g} / \mathrm{d}$ ). Differences were $108.6 \mathrm{~g} / \mathrm{d}$ for daily feed intake (compared with $141.8 \mathrm{~g} / \mathrm{d}$ ), $0.19 \mathrm{~kg} / \mathrm{kg}$ for feed conversion ratio (compared with $0.18 \mathrm{~kg} / \mathrm{kg}$ ), $-4.1 \mathrm{~g} / \mathrm{d}$ for ADG (compared with $7.0 \mathrm{~g} / \mathrm{d}$ ), $-1.44 \%$ for LMC (compared with $-1.05 \%$ ), and 3.66 points for the meat quality index (compared with 3.19). Tested on the contemporary groups, all traits but ADG were significantly different between the lines.

In the INRA experimental facilities at Saint-Gilles, animals were kept for $12 \mathrm{~d}$ before slaughter in pens equipped with collective feeders, and feed composition was similar to that delivered in Rouillé. Because muscle glycogen is a labile compound that can be quickly metabolized during preslaughter stress and postmortem processing, biopsies from the LM were taken $8 \mathrm{~d}$ before slaughter without any fasting or stress to assess in vivo muscle glycogen content and its distribution among myofibers. The LM biopsies, approximately $500 \mathrm{mg}$, were taken at the level of the last rib curvature, $8 \mathrm{~cm}$ from the midline. The entire biopsy procedure was carried out within a few minutes using a shot-biopsy device (Biotech, Nitra, Slovakia) as described previously (Geverink et al., 1999; Hamilton et al., 2002; Damon et al., 2006), and approved by the French Veterinary Services (Damon et al., 2006). Immediately after sampling, the collected biopsies were trimmed of fat and skin, oriented according to muscle fiber longitudinal axis, embedded in Tissue-Tek OCT compound (Sakura, Tokyo, Japan) on a piece of cork, frozen in 2-methylbutane (isopentane) prechilled with liquid nitrogen, and stored at $-80^{\circ} \mathrm{C}$ until further processing. Pigs were slaughtered $8 \mathrm{~d}$ after the biopsy in our INRA experimental slaughterhouse (Saint-Gilles, France) after a very short individual transportation (about $300 \mathrm{~m}$ ) and without any previous fasting or stress (no mixing of animals) to limit preslaughter glycogen breakdown, and thus be as close as possible to the in vivo physiological situation. Our experimental facilities allowed increased standardization of preslaughter and slaughter conditions.

\section{Carcass Traits and Organ Weights}

Weights of hot carcass, rhomboideus muscle (RM), heart, liver, and thyroid gland were recorded at slaugh- 
ter. After $24 \mathrm{~h}$ at $4^{\circ} \mathrm{C}$, wholesale cuts of the left halfcarcass (ham, shoulder, belly, loin, and backfat) were weighed. Lean meat content was estimated from a linear combination of the weights of the ham, loin, and backfat, and expressed as a percentage of the half-carcass weight using the equation $\mathrm{LMC}=5.684+1.197 \%$ (ham) $+1.076 \%$ (loin) $-1.059 \%$ (backfat) (Métayer and Daumas, 1998). The whole LM was dissected from the left loin and weighed.

\section{Meat Quality Traits}

Thirty minutes after slaughter, samples of LM (3rd/4th lumbar vertebra level), semimembranosus (SM), biceps femoris (BFM), and RM were taken, mounted on tongue depressors, frozen in isopentane prechilled with liquid nitrogen, and stored at $-80^{\circ} \mathrm{C}$ until further processing. The $\mathrm{pH}$ at $30 \mathrm{~min}$ postmortem was determined on LM, SM, and BFM muscles after homogenization of $2 \mathrm{~g}$ of muscle in $18 \mathrm{~mL}$ of $5 \mathrm{mM}$ iodoacetate (Ingold Xerolyte electrode, Knick pH-meter, Berlin, Germany). Muscle glycolytic potential (GP), a trait directly related to in vivo muscle glycogen content at the time of slaughter, defined as GP $=2$ ([glycogen] + [glucose $]+$ [glucose $6 \mathrm{P}])+$ [lactate $]$, was measured on LM, SM, BFM, and RM and expressed as micromoles of lactate equivalents per gram of fresh tissue (Lebret et al., 2006). The next day, ultimate $\mathrm{pH}(\mathrm{pH} 24$ $\mathrm{h}$ postmortem) was measured directly in LM, SM, and BFM muscles using the same $\mathrm{pH}$ meter as described above. The CIE $\mathbf{L}^{*}$ (lightness), $\mathbf{a}^{*}$ (redness), and $\mathbf{b}^{*}$ (yellowness) parameters were determined in triplicate in the central part of LM, SM, and BFM muscles at 24 $\mathrm{h}$ postmortem using a Minolta chromameter CR-300 (Osaka, Japan), with a D65 illuminant and a 1-cmdiameter aperture. A fresh section of each muscle was allowed to bloom for $1 \mathrm{~h}$ at $4^{\circ} \mathrm{C}$ under artificial light before $\mathrm{L}^{*}, \mathrm{a}^{*}$, and $\mathrm{b}^{*}$ measurements. The same day, approximately $100 \mathrm{~g}$ of LM (cranial to the last rib cut) was collected, trimmed of external fat and perimysium, weighed, and kept at $4^{\circ} \mathrm{C}$ in a plastic bag for a subsequent $24 \mathrm{~h}$ for determination of drip loss after $2 \mathrm{~d}$ postmortem (Honikel, 1998). Muscle slices were also taken on all 4 muscles, trimmed of external fat, minced, and freeze-dried before determination of intramuscular fat content after chloroform-methanol extraction, as described previously (Lebret et al., 2006). Lipid content of fresh tissue $(\mathrm{g} / 100 \mathrm{~g})$ was calculated by taking into account the DM content determined from the weight of minced tissue before and after freeze-drying.

\section{Skeletal Muscle Biological Traits}

Histological Analyses. Histological measurements were performed on $10-\mu \mathrm{m}$-thick serial transverse sections cut on a cryostat (2800 frigocut N, Reichert-Jung, Heidelberg, Germany) at $-20^{\circ} \mathrm{C}$. Histoenzymology was undertaken on both biopsies and 30-min postmortem samples of LM. One muscle serial section was stained using the conventional acto-myosin-ATPase histochemistry after preincubation at $\mathrm{pH} 4.35$ to identify types I, IIA, and IIB fibers, and another one was processed for succino-dehydrogenase to identify red oxidative $(\mathbf{R})$ and white glycolytic (W) fibers as described previously (Lefaucheur et al., 2004). Both I and IIA fibers are oxidative (type R), whereas IIB fibers can be either moderately oxidative (type $\mathrm{R}$ ) or not oxidative (type W). Myofibers were classified as types I, IIA, IIBR, and IIBW as a result of both stains (Larzul et al., 1997). For an accurate estimation of the proportions of types I, IIA, IIBR, and IIBW fibers, several entire bundles of myofibers from 30-min postmortem samples were selected in 3 random fields to obtain a total of at least 1,000 fibers that were counted using a projection microscope (Visopan, Reichert, Heidelberg, Germany). Immunocytochemistry was undertaken on LM biopsies using NLC-MHCs, 6B8, 8F4, and BFF3 monoclonal antibodies, specific for pig type I, IIa, IIx, and IIb myosin heavy chains (MyHC), respectively, as outlined in a previous study (Lefaucheur et al., 2004). Thus, myofibers were classified as types s, a, x, and $\mathrm{b}$ based on the presence of types I, IIa, IIx, and IIb $\mathrm{MyHC}$, respectively. Hybrid sa, ax, and xb fibers could also be observed. On both LM biopsies and samples taken at 30 min postmortem, glycogen concentration at the myofiber level was determined on serial sections stained with the periodic acid Schiff method (Pearse, 1968) using luminance (256 gray levels scale) determined by computerized image processing (Fernandez et al., 1995). Indeed, these previous reports showed that luminance of the periodic acid Schiff staining was closely related to glycogen content. An additional serial section was stained with azorubine to uniformly stain the myofibers in red, but keeping the interfiber network unstained, which allowed the extraction of the interfiber network by computerized image analysis. A total of 500 fibers from 3 random fields were used to evaluate glycogen content and cross-sectional area (CSA) of the different fiber types classified by histoenzymology or immunocytochemistry or both on biopsies and 30-minpostmortem samples of LM.

Biochemical Analyses. Activities of lactate dehydrogenase (LDH), citrate synthase (CS), and $\beta$-hydroxy-acyl-CoA dehydrogenase (HAD) were determined on LM, SM, BFM, and RM samples taken at 30 min postmortem as described previously (Lebret et al., 1999). These enzymes were chosen to assess the glycolytic pathway, Krebs cycle activity, and fatty acid $\beta$-oxidation potential, respectively. Activities were measured at $30^{\circ} \mathrm{C}$ and expressed as micromoles of substrate degraded per minute per gram of fresh tissue. Expression of genes coding for uncoupling proteins 2 and 3 (UCP2 and 3, respectively) was investigated on a subset of 6 animals from each line by real-time reversetranscription PCR (Damon et al., 2006). The potential of mitochondrial respiration was measured on fresh thin bundles of 20 to 30 permeabilized myofibers from LM taken immediately after slaughter to determine the 
maximal rate of oxygen consumption and respiratory control ratio (RCR; i.e., the ADP-activated state III respiration/state IV respiration), using a 2-chamber high resolution respirometer (Oroboros oxygraph-2k, Innsbruck, Austria; Gueguen et al., 2005). Because respiration measurements had to be done on fresh myofibers, subsets of 4 animals from each RFI line were analyzed.

\section{Hormone and Metabolite Concentrations}

Ten milliliters of blood was collected on all pigs in the home pen 2 wk before slaughter via jugular venipuncture into heparinized (20 IU of heparin/mL of blood) in the morning after an overnight fasting (fasted animals), and on all pigs at exsanguination at the slaughterhouse without any previous fasting (fed animals). Blood was centrifuged at $2,500 \times g$ for $10 \mathrm{~min}$ at $4^{\circ} \mathrm{C}$ and plasma was stored at $-20^{\circ} \mathrm{C}$ until further analysis. All samples were analyzed within a single assay. Except for glucose, plasma determinations were undertaken on both fasted and fed pigs. Concentrations of plasma IGF-I were determined using a validated RIA (Louveau and Bonneau, 1996) that used recombinant human IGF-I (GroPep, Adelaïde, Australia). The quantification limit of the assay was $0.08 \mathrm{ng} / \mathrm{mL}$, and the intra- and interassay CV were 7 and $15 \%$, respectively, at $302 \mathrm{ng} / \mathrm{mL}$. Plasma leptin was measured using the multi-species RIA kit (Linco Research, St. Charles, MO) previously validated for use in porcine plasma (Qian et al., 1999). The quantification limit of the assay was $1 \mathrm{ng} / \mathrm{mL}$, and the intra- and interassay CV were 5 and $14 \%$, respectively, at $1.82 \mathrm{ng} / \mathrm{mL}$. The plasma concentrations of total $(\mathbf{T})$ thyroxine $\left(\mathbf{T}_{4}\right)$, T triiodothyronine $\left(\mathbf{T}_{3}\right)$, and free $\mathrm{T}_{3}\left(\mathbf{F T}_{3}\right)$ were determined using RIA kits (M.P. Biomedicals, Illkirch, France). The quantification limits of the assays were $7.6 \mathrm{ng} / \mathrm{mL}, 0.07 \mathrm{ng} / \mathrm{mL}$, and 0.09 fmol $/ \mathrm{mL}$ for $\mathrm{TT}_{4}, \mathrm{TT}_{3}$, and $\mathrm{FT}_{3}$, respectively. The intra- and interassay CV were 8.1, 5.6, 8.4 and 11.3, $7.5,8.9 \%$ at $7.6 \mathrm{ng} / \mathrm{mL}, 1 \mathrm{ng} / \mathrm{mL}$, and $2.3 \mathrm{fmol} / \mathrm{mL}$, respectively. Plasma cortisol was determined using a competitive ${ }^{125}$ I RIA kit (Immunotech, Prague, Czech Republic). The quantification limit of the assay was $5 \mathrm{ng} / \mathrm{mL}$, and the intra- and interassay CV were 4.2 and $10.0 \%$ at $71 \mathrm{ng} / \mathrm{mL}$, respectively. Plasma glucose concentration was measured only on fasted pigs using a commercial kit (Glucose HK, Thermo Electron, Cergy Pontoise, France). Saliva was collected on all pigs in the home pen, in the morning after an overnight fasting. Saliva cortisol was measured with a luminescence immunoassay kit (IBL, Hamburg, Germany). The quantification limit of the assay was $0.16 \mathrm{ng} / \mathrm{mL}$. The intraand interassay $\mathrm{CV}$ were 6.1 and $7.8 \%$ at $2.1 \mathrm{ng} / \mathrm{mL}$, respectively.

\section{Statistical Analyses}

The SAS software (SAS Inst. Inc., Cary, NC) was used in all statistical analyses of the data. For growth performance, muscle chemical composition, meat quality traits, and metabolic enzyme activities, data were first analyzed by a 2-way ANOVA using the GLM procedure of SAS, with the RFI group (pigs from the low vs. high RFI line) and slaughter day as main effects. The effect of the slaughter day was removed from the final model because it did not significantly influence any of the characteristics studied, likely due to the increased standardization of our preslaughter and slaughter conditions. The model used to study the effects of RFI line on raw muscle and organ weight data included RFI line as fixed effect, carcass weight as a covariate, and their interaction. For histological characteristics of LM, data were submitted to a 2-way ANOVA, with the RFI group, fiber type, and their interaction as main effects. For hormone concentrations, the effects of the RFI group were analyzed by a 1-way ANOVA within each nutritional status (fed or overnight fasted). Differences in hormone concentrations between the fed and overnight fasted states were analyzed using the paired Student's $t$-test, each animal being its own control. To assess the validity of the muscle sampling technique to predict in vivo characteristics of the muscle, the differences for myofiber CSA and glycogen content between muscle biopsies taken at $8 \mathrm{~d}$ before slaughter and muscle samples at $30 \mathrm{~min}$ after slaughter on the same animals were analyzed using the paired Student's $t$-test. In addition, different traits were sometimes included as covariates in the statistical models to refine the interpretation of the overall differences between RFI groups. Significant effects were those with $P<0.05$, and marginally significant effects were those with $P<0.1$.

\section{RESULTS}

\section{Growth Performance, Carcass Traits, and Organ Weights}

Animals from both lines were slaughtered at similar BW and age (Table 1), and ADG did not differ significantly between RFI groups. Pigs from the low RFI line exhibited leaner carcasses, as reflected by a greater LMC $(P<0.0001)$ and loin:backfat ratio $(P<0.001)$. The proportion of backfat, expressed as a percentage of carcass weight, decreased by $24 \%$, whereas weight of LM increased by $13 \%(P<0.001)$ in pigs from the low compared with the high RFI line. In contrast, RM, heart and liver weights were not affected by the RFI line. The weight of thyroid gland was $19.4 \%$ lighter $(P$ $=0.01)$ in animals from the low compared with the high RFI line.

\section{Meat Quality Traits}

Low RFI line pigs exhibited about 30\% less intramuscular fat content in all 4 muscles, LM, SM, BFM, and RM, than high RFI line pigs (Table 2). The opposite was observed for GP, which was $17 \%$ greater in 
Table 1. Growth performance of pigs from low and high residual feed intake (RFI) lines

\begin{tabular}{lcccc}
\hline \hline & $\begin{array}{c}\text { Low RFI line } \\
(\mathrm{n}=14)\end{array}$ & $\begin{array}{c}\text { High RFI line } \\
(\mathrm{n}=13)\end{array}$ & RSD $^{1}$ & $P$-value \\
Item & -54.2 & 22.5 & 13.8 & $<0.001$ \\
\hline RFI, g/d (genetic values) & & & & \\
Growth traits & 27.7 & 27.6 & 3.9 & 0.948 \\
Initial BW, kg & 109.5 & 106 & 7.9 & 0.252 \\
Final BW, kg & 179.1 & 179.6 & 1.8 & 0.437 \\
Final age, d & 795 & 762 & 69 & 0.24 \\
ADG, g/d & & & & \\
Carcass trait & 91.9 & 87 & 7 & 0.08 \\
HCW, kg & 58.6 & 54 & 2.6 & $<0.001$ \\
LMC, \% & 29.2 & 27.2 & 1.1 & $<0.001$ \\
Loin, \% & 5.94 & 7.8 & 1.24 & $<0.001$ \\
Backfat, \% & 4.98 & 3.67 & 0.82 & $<0.001$ \\
Loin:backfat & & & & $<0.001$ \\
Muscle and organ weight, g & 2,879 & 2,541 & 212 & 0.398 \\
LM & 43.5 & 46.1 & 7.3 & 0.772 \\
Rhomboideus & 377 & 372 & 44 & 0.964 \\
Heart & 2,067 & 2,064 & 187 & 0.01 \\
Liver & 6.98 & 8.66 & 1.46 & \\
Thyroid gland & & & \\
\hline
\end{tabular}

${ }^{1}$ Residual SD (root mean square error of the full ANOVA model).

${ }^{2}$ Probability of a type I error.

${ }^{3} \mathrm{ADG}$ during the growing-finishing period (i.e., from $27.7 \mathrm{~kg}$ to slaughter).

${ }^{4}$ Lean meat content.

LM, SM, and BFM of pigs from the low RFI line $(P<$ $0.04)$, with no significant difference in the RM between lines. The $\mathrm{pH} 30 \mathrm{~min}$ and $24 \mathrm{~h}$ postmortem were only measured in LM, SM, and BFM. No difference between RFI groups was observed for $\mathrm{pH} 30$ min, whereas $\mathrm{pH}$ $24 \mathrm{~h}$ postmortem was significantly less in LM $(-0.16$ $\mathrm{pH}$ unit) and BFM (-0.12 pH unit) in low compared with high RFI line pigs. The same trend occurred in SM (-0.09 pH units) but did not reach statistical significance $(P=0.19)$. The low RFI line animals had significantly greater $\mathrm{L}^{*}$ values in $\mathrm{LM}, \mathrm{SM}$, and BFM, which was associated with a greater LM drip loss assessed at $2 \mathrm{~d}$ postmortem (2.13 vs. $1.15 \% ; P=0.04$ ). The redness parameter $\left(\mathrm{a}^{*}\right)$ did not differ between RFI groups in any muscle, whereas yellowness $\left(b^{*}\right)$ tended to be greater only in LM of pigs from the low vs. high RFI line.

\section{Metabolic Enzyme Activities}

The LM, SM, and BFM are mostly glycolytic muscles (greater LDH activity), with an increasing oxidative capacity in the rank order $\mathrm{LM}<\mathrm{SM}<\mathrm{BFM}$, whereas $\mathrm{RM}$ muscle is mostly oxidative (greater CS and HAD activities) and poorly glycolytic. The activities of LDH and CS were not significantly different between RFI groups in any muscle (Table 3 ). Only HAD activity, an indicator of fatty acid $\beta$-oxidation potential, tended $(P<0.1)$ to be greater in LM, SM, and BFM of high than low RFI line pigs, whereas no difference between lines was observed in RM. Data from a subset of animals from each line did not show any significant difference between lines for the expression of genes coding for UCP2 and $3(\mathrm{n}=6)$, or the potential and regulation of mitochondrial respiration (maximal rate, state III, state IV, RCR; $\mathrm{n}=4$; data not shown).

\section{Myofiber Characteristics in LM}

Myofiber Typing Technology. Four fiber types (i.e., I, IIA, IIBR, and IIBW) were identified by conventional histoenzymology combining actomyosin-ATPase and succino-dehydrogenase staining on serial sections (Figure 1A, B). On average, LM contained 12.4, 6.1, 7.8 , and $73.7 \%$ of I, IIA, IIBR, and IIBW fibers, respectively. Using monoclonal antibodies specific of each $\mathrm{MyHC}$, fibers could be classified as types s, a, x, and $\mathrm{b}$ based on the presence of MyHC I, IIa, IIx, and IIb, respectively (Figure $1 \mathrm{C}$ to $1 \mathrm{~F}$ ). Moreover, some hybrid sa, ax, and xb fibers could be observed. Thus, on average, LM contained $12.9 \%$ s, $0.9 \%$ sa, $5.9 \%$ a, $5.2 \%$ ax, $9.0 \% \mathrm{x}, 13.5 \% \mathrm{xb}$, and $52.6 \%$ pure b fibers. The correspondence between both myofiber classifications (i.e., histoenzymology vs. immunocytochemistry) is shown on Figure 2. Most I and IIA fibers contained type $\mathrm{s}$ (97\%) or type a (87\%) MyHC, respectively, which suggested a relatively good correspondence between both classifications for these fibers. In contrast, type IIBW fibers were a mixture of $\mathrm{b}(71 \%), \mathrm{xb}(18 \%)$, and $\mathrm{x}(11 \%)$ fibers and about $65 \%$ of IIBR fibers corresponded to hybrid ax fibers, and $23 \%$ to x fibers. Thus, $85 \%$ of type $\mathrm{x}, 97 \%$ of type $\mathrm{xb}$, and $100 \%$ of type $\mathrm{b}$ fibers were IIBW fibers, showing that conventional fiber typing using histoenzymology (I, IIA, IIBR, IIBW) could not make any distinction between types $\mathrm{x}, \mathrm{xb}$, and $\mathrm{b}$ fibers under our experimental conditions. 
Table 2. Muscle chemical composition and meat quality traits of LM, semimembranosus (SM), biceps femoris (BFM), and rhomboideus (RM) muscles in pigs from low and high residual feed intake (RFI) lines

\begin{tabular}{|c|c|c|c|c|}
\hline Item & $\begin{array}{l}\text { Low RFI line } \\
\quad(\mathrm{n}=14)\end{array}$ & $\begin{array}{l}\text { High RFI line } \\
\quad(\mathrm{n}=13)\end{array}$ & $\mathrm{RSD}^{1}$ & $P$-value ${ }^{2}$ \\
\hline \multicolumn{5}{|c|}{ Intramuscular fat, $\%$} \\
\hline LM & 1.21 & 1.79 & 0.37 & $<0.001$ \\
\hline SM & 1.66 & 2.43 & 0.91 & 0.039 \\
\hline $\mathrm{BFM}$ & 1.43 & 2.11 & 0.43 & $<0.001$ \\
\hline $\mathrm{RM}$ & 1.88 & 2.37 & 0.55 & 0.032 \\
\hline \multicolumn{5}{|c|}{ Glycolytic potential $^{3}$} \\
\hline LM & 162 & 138 & 21 & 0.007 \\
\hline $\mathrm{SM}$ & 144 & 123 & 19 & 0.009 \\
\hline $\mathrm{BFM}$ & 149 & 127 & 26 & 0.04 \\
\hline $\mathrm{RM}$ & 91 & 83 & 21 & 0.365 \\
\hline \multicolumn{5}{|c|}{ pH 30 min postmortem } \\
\hline $\mathrm{LM}$ & 6.35 & 6.45 & 0.15 & 0.092 \\
\hline SM & 6.44 & 6.49 & 0.19 & 0.423 \\
\hline BFM & 6.42 & 6.43 & 0.15 & 0.823 \\
\hline \multicolumn{5}{|c|}{ pH $24 \mathrm{~h}$ postmortem } \\
\hline LM & 5.42 & 5.58 & 0.1 & 0.001 \\
\hline SM & 5.5 & 5.59 & 0.18 & 0.187 \\
\hline $\mathrm{BFM}$ & 5.51 & 5.63 & 0.14 & 0.052 \\
\hline \multicolumn{5}{|l|}{$\mathrm{L}^{*}$} \\
\hline LM & 54.1 & 50.7 & 2.5 & 0.002 \\
\hline $\mathrm{SM}$ & 53.3 & 50.4 & 3.8 & 0.057 \\
\hline BFM & 50.4 & 47.7 & 3.1 & 0.036 \\
\hline \multicolumn{5}{|l|}{$a^{*}$} \\
\hline LM & 7.78 & 7.63 & 1.2 & 0.749 \\
\hline $\mathrm{SM}$ & 8.93 & 8.89 & 1.94 & 0.951 \\
\hline $\mathrm{BFM}$ & 10.14 & 10.62 & 1.69 & 0.466 \\
\hline \multicolumn{5}{|l|}{$\mathrm{b}^{*}$} \\
\hline $\mathrm{LM}$ & 5.79 & 4.94 & 1.17 & 0.068 \\
\hline SM & 7.92 & 6.38 & 3.17 & 0.218 \\
\hline BFM & 7.23 & 6.6 & 1.31 & 0.23 \\
\hline \multicolumn{5}{|c|}{ Drip loss $2 \mathrm{~d}$ postmortem, $\%$} \\
\hline LM & 2.13 & 1.15 & 1.18 & 0.041 \\
\hline
\end{tabular}

${ }^{1}$ Residual SD (root mean square error of the full ANOVA model).

${ }^{2}$ Probability of a type I error.

${ }^{3}$ Expressed as micromoles of lactate equivalents per gram of fresh muscle.

Table 3. Metabolic enzyme activities of lactate dehydrogenase (LDH), citrate synthase (CS), and $\beta$-hydroxy-acyl-CoA dehydrogenase (HAD) in LM, semimembranosus (SM), biceps femoris (BFM), and rhomboideus (RM) muscles of pigs from low and high residual feed intake (RFI) lines ${ }^{1}$

\begin{tabular}{lcccc}
\hline \hline Item & $\begin{array}{c}\text { Low RFI line } \\
(\mathrm{n}=14)\end{array}$ & $\begin{array}{c}\text { High RFI line } \\
(\mathrm{n}=13)\end{array}$ & RSD $^{2}$ & $P$-value \\
\hline LDH & & & & \\
LM & 2,310 & 2,407 & 262 & 0.349 \\
SM & 2,335 & 2,252 & 221 & 0.337 \\
BFM & 1,946 & 1,811 & 199 & 0.089 \\
RM & 524 & 521 & 113 & 0.951 \\
CS & & & & 0.307 \\
LM & 5.58 & 5.98 & 1.14 & 0.256 \\
SM & 9.29 & 9.8 & 2.18 & 0.137 \\
BFM & 12.6 & 13.9 & 1.43 & 0.631 \\
RM & 16.5 & 16.7 & & \\
HAD & & & 0.51 & 0.086 \\
LM & 2.36 & 2.71 & 0.6 & 0.093 \\
SM & 4.43 & 4.83 & 1.2 & 0.064 \\
BFM & 5.42 & 6.31 & 1.17 & 0.826 \\
RM & 11.4 & 11.5 & & \\
\hline
\end{tabular}

${ }^{1}$ Activities expressed as micromoles of substrate per minute per gram of fresh muscle.

${ }^{2}$ Residual SD (root mean square error of the full ANOVA model).

${ }^{3}$ Probability of a type I error. 

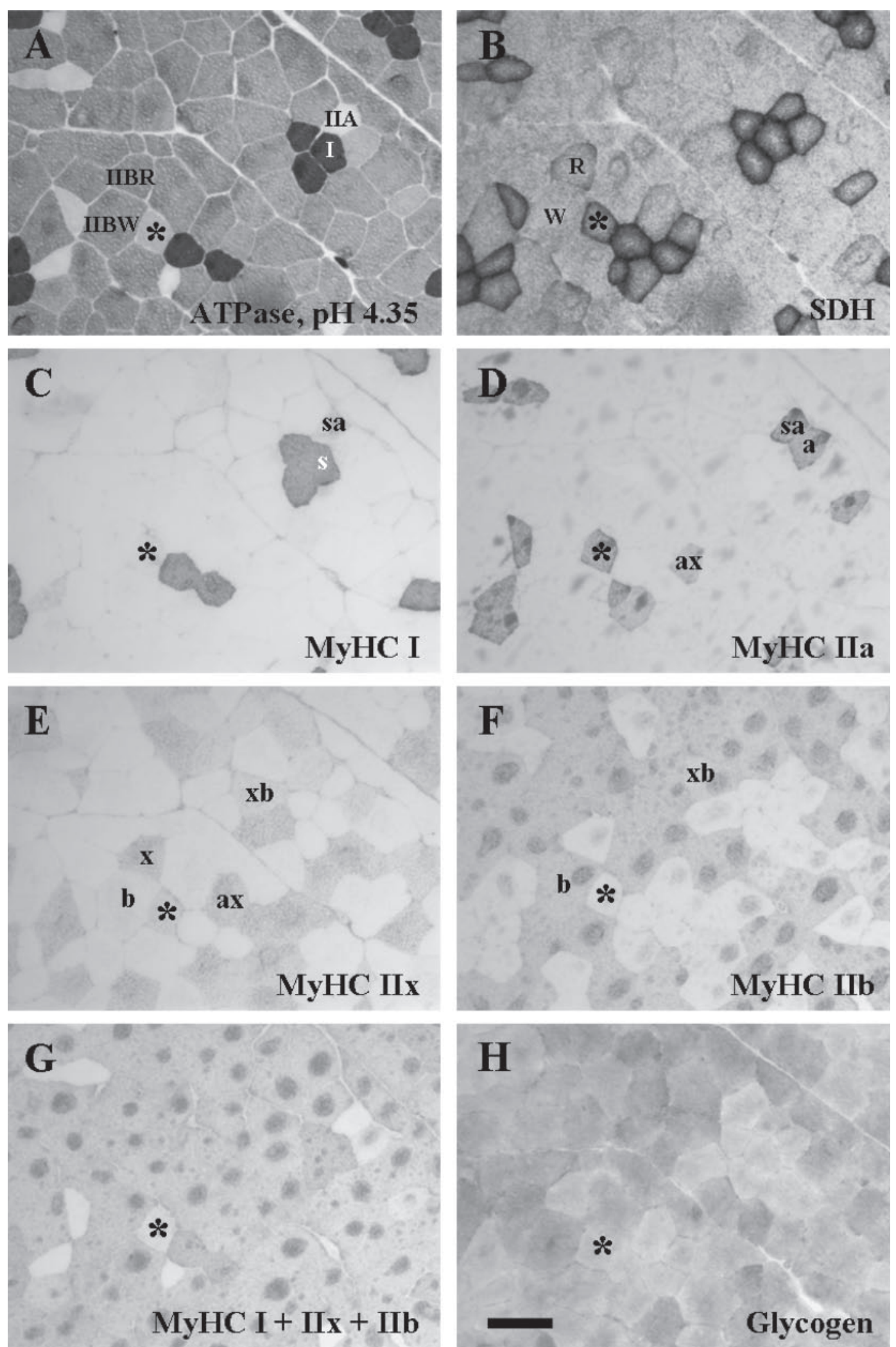

Figure 1. Identification of fiber types by enzyme histochemistry and immunocytochemistry on serial transverse frozen sections of LM sampled at $30 \mathrm{~min}$ after slaughter. Histochemical determination of actomyosin ATPase after preincubation at pH 4.35 (A) and succino-dehydrogenase (SDH; B). Immunocytochemical staining with type I (C), IIa (D), IIx (E), IIb (F), and I + IIx + IIb (G) monoclonal antibodies. Glycogen staining with periodic acid Shiff (H). Myofibers are classified as types I, IIA, and IIB (A); red oxidative (R) and white glycolytic (W) fibers (B); or s, a, x, and $\mathrm{b}$ based on the presence of myosin heavy chain (MyHC) I, IIa, IIx, and IIb, respectively (C to F). The star symbol denotes a corresponding fiber on the serial sections. Bar $=100 \mu \mathrm{m}$. 


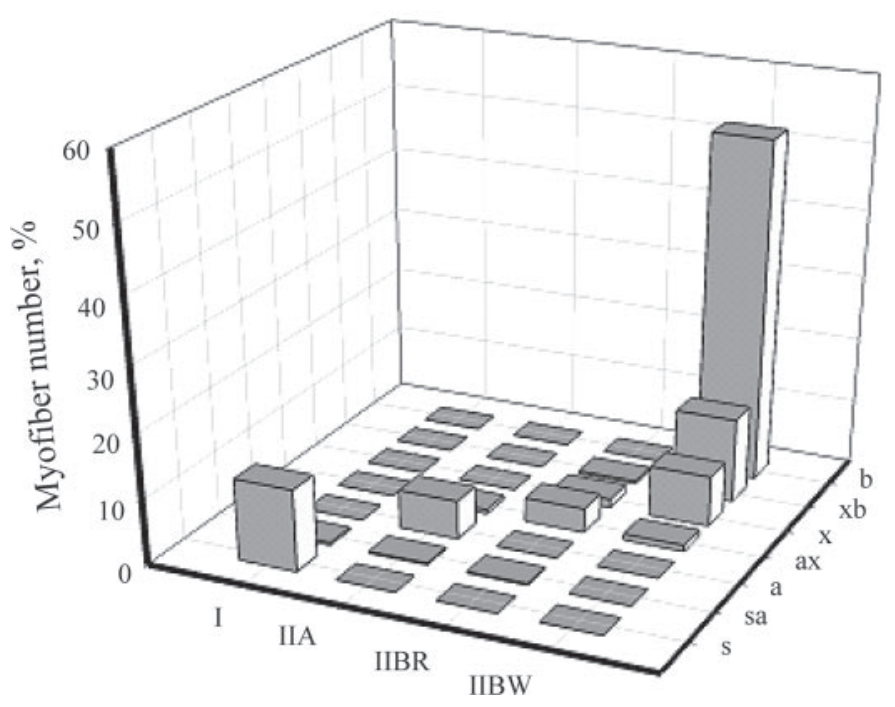

Figure 2. Histochemical fiber type classification as types I, IIA, IIBR, and IIBW plotted vs. presence of the myosin heavy chains s, a, $\mathrm{x}$, and $\mathrm{b}$ revealed by immunocytochemistry on serial transverse sections of LM.

Muscle Sampling Technology. In the present study, one of the main objectives was to quantify glycogen content within myofibers according to their contractile and metabolic types to explain the genetic correlation between RFI and ultimate $\mathrm{pH}$. The comparisons between muscle biopsies taken at $8 \mathrm{~d}$ before slaughter and muscle samples at 30 min after slaughter for myofiber CSA and intrafiber glycogen content according to I, IIA, IIBR, and IIBW fiber types are shown in Figure 3. On average, intrafiber glycogen content was $1.26 \%$ in muscle biopsies and $0.82 \%$ in 30-minpostmortem samples, denoting a $35 \%$ decrease in glycogen content within 30 min postmortem. No significant difference in the decrease of glycogen content was observed between the different fiber types. Therefore, to be close to the in vivo situation, priority was given to results obtained on muscle biopsies to assess the influence of divergent selection for RFI on myofiber glycogen content with respect to both fiber type classifications [i.e., histoenzymology (I, IIA, IIBR, IIBW) and immunocytochemistry based on MyHC composition ( $\mathrm{s}$, sa, a, ax, $\mathrm{x}, \mathrm{xb}$, and b)]. Because myofiber typing on serial sections is tedious and time consuming, myofibers were only classified as types I, IIA, IIBR, and IIBW in 30-min-postmortem samples to make comparisons with biopsies taken at $8 \mathrm{~d}$ before slaughter. Regarding CSA of myofibers, we noticed an artifactual $52 \%$ increase in CSA of all fiber types (Figure 3A) in muscle biopsies compared with 30-min postmortem samples, likely due to the fact that myofibers contracted during the quick conditioning and freezing of muscle biopsies, whereas such contraction was not present at 30 min postmortem. Therefore, the influence of divergent selection for RFI on myofiber CSA was evaluated only on muscle samples taken at 30 min postmortem.

Influence of Divergent Selection for RFI on Histological Traits. Compared with high RFI line pigs, animals from the low RFI line exhibited greater proportions of fast-twitch glycolytic type IIBW (75.5 vs. $71.9 \% ; P=0.016)$ and pure type $\mathrm{b} \mathrm{MyHC}$ fibers (54.1 vs. $51.2 ; P=0.06$; Table 4 ). Animals from the low RFI line also tended to have less IIBR fibers $(P=$ $0.08)$, suggesting a shift to a more glycolytic phenotype. Selection for low RFI induced a $23 \%$ general increase in myofiber CSA, in particular of type II fibers. As a combination of changes in fiber type proportions and myofiber CSA, the relative area of IIBW fibers was slightly greater in pigs from the low than high RFI line $(P=0.06)$. On average, within myofiber glycogen content assessed by image analysis in muscle biopsy samples was $1.38 \%$ in low RFI line pigs, and $1.11 \%$ in the high RFI line pigs (Figure 4), corresponding to $25 \%$ more glycogen in the former group $(P<0.001)$. As shown by a highly significant RFI group $\times$ fiber type interaction $(P<0.001)$, the influence of RFI group on myofiber glycogen content differed according to fiber types (Figure 4). Thus, glycogen content increased by $30 \%$ in glycolytic fibers (IIBW, x, xb, and b), 23 to $26 \%$ in IIBR and ax fibers, and only 16 to $18 \%$ in IIA and a fibers, whereas no significant changes were observed between RFI groups in types I, s, and sa fibers. This led to a greater heterogeneity of glycogen content between fiber types in low RFI (IIBW > IIBR = IIA > I) than high RFI line pigs where weaker differences between fiber types could be observed (Figure 4A). When differences between RFI groups were assessed on muscle samples taken 30 min postmortem, only IIBW fibers tended to contain more glycogen in low than high RFI
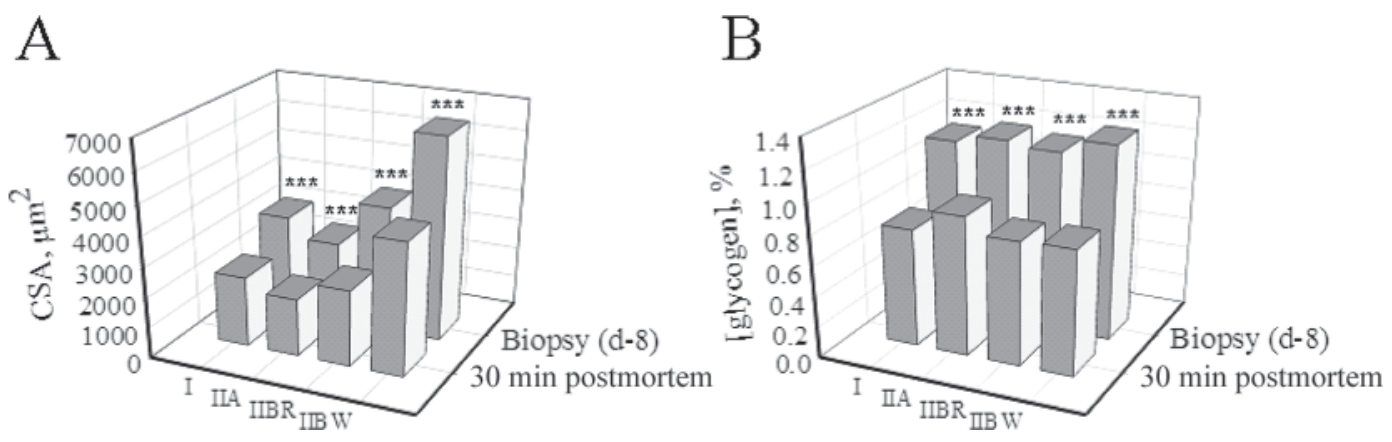

Figure 3. Cross-sectional area (CSA; A) and glycogen content (B) of types I, IIA, IIBR, and IIBW myofibers in LM sampled at 8 d before slaughter (biopsy) or 30 min postmortem. Level of significance: $* * * P<0.001$. 

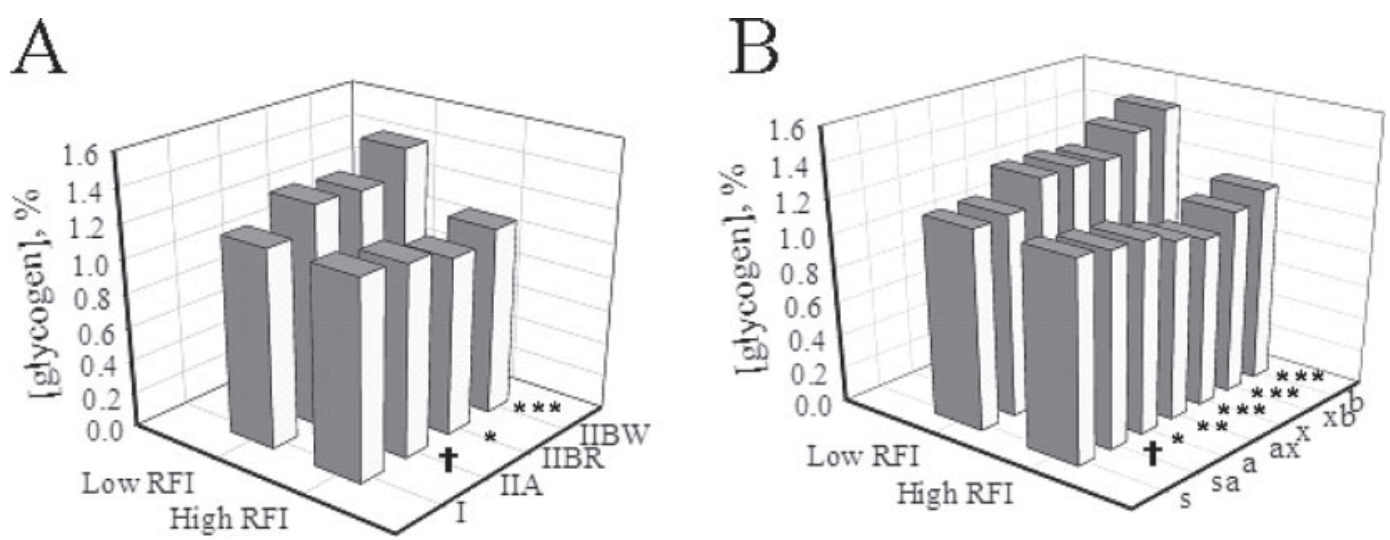

Figure 4. Glycogen content of myofibers in LM biopsies taken at $8 \mathrm{~d}$ before slaughter in pigs with low and high residual feed intake (RFI). Myofibers were classified as type I, IIA, IIBR, and IIBW (A) or based on the presence of the myosin heavy chains s, a, x, and b (B). Levels of significance: ${ }^{* * *} P<0.001 ; * * P<0.01 ;{ }^{*} P<0.05 ; \dagger P<0.10$.

line pigs ( 0.95 vs. $0.75 \%, P=0.08$; data not shown). Thus, the line difference in myofiber glycogen content was stronger when evaluated on LM biopsies taken at 8 d preslaughter than on muscle samples taken at $30 \mathrm{~min}$ after slaughter.

\section{Hormone Concentrations}

Plasma concentrations in IGF-I were not affected by either the nutritional status (fed vs. overnight fasted) or the RFI group (Table 5). Plasma leptin was not influenced by the nutritional status, but was significantly increased $(P=0.04)$ in pigs from the high vs. low RFI line in the fed state, whereas differences between lines were not significant in the fasted state. Total $\mathrm{T}_{4}, \mathrm{TT}_{3}$, and $\mathrm{FT}_{3}$ were all significantly increased $(P<0.001)$ in the fed vs. fasted state. Pigs from the low RFI line tended to exhibit greater $\mathrm{TT}_{4}$ and $\mathrm{FT}_{3}$ concentrations $(P<0.10)$ than high RFI line pigs in the fed state, whereas no line difference were observed in the fasted

Table 4. Histochemical characteristics of LM of pigs from low and high residual feed intake (RFI) lines

\begin{tabular}{lcccc}
\hline \hline & $\begin{array}{c}\text { Low RFI line } \\
(\mathrm{n}=14)\end{array}$ & $\begin{array}{c}\text { High RFI line } \\
(\mathrm{n}=13)\end{array}$ & RSD $^{1}$ & $P_{\text {-value }}{ }^{2}$ \\
Item & & & & \\
\hline Proportion of fiber types, ${ }^{3} \%$ & 11.7 & 13 & 4.4 & 0.452 \\
I & 5.78 & 6.53 & 2.66 & 0.468 \\
IIA & 7.04 & 8.51 & 2.13 & 0.085 \\
IIBR & 75.5 & 71.9 & 3.6 & 0.017 \\
IIBW & 12.1 & 13.9 & 3.7 & 0.23 \\
s & 0.95 & 0.77 & 0.66 & 0.478 \\
sa & 5.77 & 6.06 & 2.73 & 0.792 \\
a & 4.77 & 5.7 & 2.46 & 0.346 \\
ax & 8.16 & 9.7 & 3.33 & 0.252 \\
x & 14.2 & 12.7 & 3.2 & 0.255 \\
xb & 54.1 & 51.2 & 3.7 & 0.059 \\
b & & & & \\
Cross-sectional area ${ }^{4}{ }^{4} \mu m^{2}$ & 2,457 & 2,142 & 450 & 0.081 \\
I & 2,175 & 1,545 & 336 & $<0.001$ \\
IIA & 2,832 & 2,134 & 757 & 0.025 \\
IIBR & 4,718 & 3,937 & 781 & 0.016 \\
IIBW & 4,163 & 3,385 & 683 & 0.006 \\
Mean & & & & \\
Relative area, $\%$ & 6.82 & 8.16 & 2.72 & 0.215 \\
I & 2.99 & 2.91 & 1.21 & 0.87 \\
IIA & 4.69 & 5.4 & 1.64 & 0.271 \\
IIBR & 85.5 & 83.5 & 2.6 & 0.062 \\
IIBW & & &
\end{tabular}

\footnotetext{
${ }^{1}$ Residual SD (root mean square error of the full ANOVA model).

${ }^{2}$ Probability of a type I error.

${ }^{3}$ I, IIA, IIBR, and IIBW fibers: histoenzymatic classification on muscle samples taken 30 min postmortem. Types s, sa, a, ax, x, xb, and b: immunocytochemical classification based on myosin heavy chain composition on muscle biopsies taken 1 wk before slaughter.

${ }^{4}$ Cross-sectional area of muscle fibers determined on muscle samples taken at 30 min postmortem.
} 
Table 5. Concentrations of growth factors, hormones, and metabolites in fed and overnight-fasted pigs from low and high residual feed intake (RFI) lines

\begin{tabular}{|c|c|c|c|c|}
\hline Item $^{1}$ & $\begin{array}{l}\text { Low RFI line } \\
\quad(\mathrm{n}=14)\end{array}$ & $\begin{array}{l}\text { High RFI line } \\
\quad(\mathrm{n}=13)\end{array}$ & $\mathrm{RSD}^{2}$ & $P$-value ${ }^{3}$ \\
\hline \multicolumn{5}{|l|}{ Fed animals } \\
\hline \multicolumn{5}{|l|}{ Blood plasma } \\
\hline IGF-I, ng/mL & 145 & 147 & 50 & 0.916 \\
\hline Leptin, $\mathrm{ng} / \mathrm{mL}$ & 2.40 & 2.96 & 0.66 & 0.038 \\
\hline $\mathrm{TT}_{4}, \mathrm{ng} / \mathrm{mL}$ & 32.5 & 28.1 & 6.4 & 0.088 \\
\hline $\mathrm{TT}_{3}, \mathrm{ng} / \mathrm{mL}$ & 1.16 & 1.04 & 0.27 & 0.271 \\
\hline $\mathrm{FT}_{3}, \mathrm{fmol} / \mathrm{mL}$ & 0.69 & 0.42 & 0.40 & 0.092 \\
\hline Cortisol, ng/mL & 64.9 & 51.2 & 22.6 & 0.129 \\
\hline \multicolumn{5}{|l|}{ Fasted animals } \\
\hline \multicolumn{5}{|l|}{ Blood plasma } \\
\hline IGF-I, ng/mL & 142 & 126 & 55 & 0.480 \\
\hline Leptin, $\mathrm{ng} / \mathrm{mL}$ & 2.57 & 2.40 & 0.53 & 0.418 \\
\hline $\mathrm{TT}_{4}, \mathrm{ng} / \mathrm{mL}$ & 25.9 & 27.3 & 4.96 & 0.473 \\
\hline $\mathrm{TT}_{3}, \mathrm{ng} / \mathrm{mL}$ & 0.85 & 0.80 & 0.26 & 0.595 \\
\hline $\mathrm{FT}_{3}, \mathrm{fmol} / \mathrm{mL}$ & 0.28 & 0.22 & 0.21 & 0.480 \\
\hline Cortisol, ng/mL & 65.1 & 52.4 & 18.1 & 0.081 \\
\hline Glucose, g/L & 0.75 & 0.76 & 0.04 & 0.460 \\
\hline \multicolumn{5}{|l|}{ Saliva } \\
\hline Cortisol, ng/mL & 1.70 & 1.93 & 0.67 & 0.387 \\
\hline
\end{tabular}

${ }^{1} \mathrm{TT}_{4}=$ total thyroxine; $\mathrm{TT}_{3}=$ total triiodothyronine; $\mathrm{FT}_{3}=$ free triiodothyronine.

${ }^{2}$ Residual SD (root mean square error of the full ANOVA model).

${ }^{3}$ Probability of a type I error.

state. Plasma cortisol was unaffected by the nutritional status and tended to be greater in pigs from the low RFI line $(P<0.10)$, whatever the nutritional state. This difference was not observed in the saliva from fasted animals. Finally, fasted plasma glucose did not differ between RFI groups.

\section{DISCUSSION}

\section{Muscle Sampling and Myofiber Typing Technologies}

Complementary analyses were used to evaluate the effects of divergent selection on muscle properties. Myofiber typing by histoenzymology (types I, IIA, IIBR, and IIBW) and immunocytochemistry (types s, sa, a, $\mathrm{ax}, \mathrm{x}, \mathrm{xb}$, and b) clearly show that types I, IIA, IIBR, and IIBW do not fully correspond to type $\mathrm{s}$, a, x, and b fibers, respectively, and that IIBW fibers are a mixture of $\mathrm{b}$, xb, and $\mathrm{x}$ MyHC-containing fibers. This confirms our previous findings obtained on skeletal muscle in LW and Meishan pigs (Lefaucheur et al., 2004), showing that these classifications are not interchangeable. From a practical point of view, both classifications are relevant and the choice between them will depend on the objectives of each study and the availability of $\mathrm{MyHC}$ monoclonal antibodies. Indeed, some antibodies are unfortunately not commercially available, in particular the IIa (6B8) and IIx (8F4) MyHC monoclonal antibodies. In the present study, because biopsies were physiologically more relevant to study in vivo muscle glycogen content, both classifications were used to study the influence of divergent selection on glyco- gen distribution among fiber types on muscle biopsies taken at $8 \mathrm{~d}$ before slaughter. Differences in muscle glycogen content between RFI groups were indeed much more significant when evaluated on muscle biopsies $(P$ $=0.0003)$ compared with 30-min-postmortem samples $(P=0.08)$. The weaker difference between RFI groups at $30 \mathrm{~min}$ postmortem is likely related to an increased uncontrolled variability of muscle glycogen content due to preslaughter and slaughter conditions, as well as to variable early postmortem glycogen breakdown. In contrast, muscle samples taken at $30 \mathrm{~min}$ postmortem were more relevant than biopsies to determine myofiber CSA, due to an artifactual myofiber contraction when conditioning muscle biopsies.

\section{Carcass LMC and Muscle Properties}

Because RFI is, by definition, phenotypically independent of BW and level of production, the present divergent selection on RFI was initially expected to have no effect on ADG and carcass composition. Thus, pigs from both RFI lines exhibited actually similar ADG, but contrary to what was initially expected, low RFI pigs also had leaner carcasses, in accordance with the genetic correlations previously reported on pigs from the same selection experiment (Gilbert et al., 2007). For different traits not measured on present animals, it could be confirmed from estimated genetic values that our low RFI pigs exhibited less feed intake and feed conversion ratio, leaner carcasses, and unaffected ADG at the genetic level. This is in agreement with other data in growing pigs indicating that selection for low RFI decreased backfat and increased LMC without 
affecting ADG (Mrode and Kennedy, 1993; Johnson et al., 1999; Nguyen et al., 2005; Hoque et al., 2007; Cai et al., 2008). Present data show that the greater LMC and LM weight of the low vs. high RFI pigs was at least partly explained by a general $23 \%$ increase in myofiber CSA, in particular of fast-twitch type II fibers. Whether an increase in the total number of fibers, a characteristic definitely fixed before birth in pigs (Wigmore and Stickland, 1983), also contributed to explain the greater LMC and LM weight of the low RFI line pigs remains to be studied. The finding of a greater proportion of glycolytic IIBW fibers in the LM of low RFI pigs is consistent with the generally accepted idea that faster lean growth is genetically associated with a greater proportion of IIBW fibers (Lefaucheur, 2010). The contribution of these differences in LMC on RFI variability remains to be asserted, but available data in cattle suggest that body composition is likely not a major contributor to variation in RFI because energy retained in the body explained only $5 \%$ of the total variation of RFI (Herd and Arthur, 2009). In this model, most variation in RFI is ascribed to differences in the efficiency of metabolic processes and heat production. Supporting this, other high RFI pigs from our selection experiment were shown to exhibit a $10 \%$ greater basal metabolism than low RFI pigs (Barea et al., 2010), in accordance with previous results reported in laying hens (Bordas et al., 1992). Beyond the decreased adiposity, we also found that pigs from the low RFI line had less intramuscular fat content in all muscles studied, in agreement with results previously reported in pigs (Cai et al., 2008) and cattle (Herd and Arthur, 2009). Based on the 0.30 positive genetic correlation reported between fatness and intramuscular fat content in pigs (de Vries et al., 1994; Sellier, 1998), the decreased intramuscular fat content in low RFI pigs was expected. However, differences in intramuscular fat content between RFI groups are likely not related to changes in fiber type composition because no consistent relationship between intramuscular fat content and fiber type composition has been documented (Lefaucheur, 2010).

\section{Hormonal Status}

To explain differences in RFI and other production traits between lines, the concentrations of several hormones were assessed. Only plasma leptin concentration and thyroid gland mass differed significantly between the 2 RFI lines. Leptin is primarily produced by adipose tissue and is involved in the regulation of feed intake (Houseknecht et al., 1998). It has been associated with decreased feed efficiency and increased fatness (Suzuki et al., 2009). This is in agreement with the current data showing a greater leptin concentration in (fatter) high RFI pigs in the fed state, and a positive phenotypic correlation between plasma leptin concentration in the fed state and backfat proportion on all 27 pigs under study $(\mathrm{r}=0.64)$. Serum leptin concentrations or leptin mRNA abundance in adipose tissue were also positively correlated with RFI in other studies using pigs (Hoque et al., 2009; Lkhagvadorj et al., 2010) and cattle (Richardson et al., 2004; Nkrumah et al., 2007; Hoque et al., 2009). However, the line difference in plasma leptin disappeared when LMC was included as a covariate in the ANOVA (data not shown), suggesting that this line difference may mostly be due to differences in body composition. Our data about plasma IGF-I are more difficult to interpret. Indeed, although IGF-I is a key player in cell proliferation and protein deposition (Florini et al., 1996), plasma concentrations in IGF-I did not differ between RFI groups, whatever the nutritional state of the animal, suggesting that plasma IGF-I measured at the end of the growing period is likely not a good predictor of RFI. In contrast, other studies did show a high positive genetic correlation (0.63) between plasma IGF-I at $35 \mathrm{~d}$ of age and RFI in a population of Yorkshire pigs (Bunter et al., 2010). Similarly, juvenile IGFI has been reported to be genetically positively related to backfat thickness and intramuscular fat content, and negatively to loin muscle area at $110 \mathrm{~kg}$ of BW (Suzuki et al., 2004; Bunter et al., 2010). Thus, contrary to IGF-I at slaughter, juvenile IGF-I seems to be a good physiological indicator of genetic merit for RFI. The increased concentrations of plasma thyroid hormones in the fed vs. fasted state is consistent with previous data (Dauncey, 1990). Because of the stimulating effects of thyroid hormones on basal energy metabolism, a less active thyroidal function can be expected in the low vs. high RFI line, as shown in cockerels (Gabarrou et al., 2000). Present data showed differences in the thyroidal function between RFI lines based on the fact that low RFI pigs had smaller thyroid glands. However, contrary to expected, low RFI pigs tended to have greater plasma $\mathrm{FT}_{3}$ and $\mathrm{TT}_{4}$ than high RFI pigs in the fed state. Another study carried out in pigs also reported a greater serum $\mathrm{TT}_{3}$ concentration in low than high RFI pigs (Lkhagvadorj et al., 2010). Further studies including more animals as well as the determination of thyroid-hormone-stimulating hormone are still needed to get a clear picture of changes in the thyroidal function between RFI lines. Finally, plasma cortisol concentrations tended $(P=0.08)$ to be greater in low than high RFI pigs, both in the fed and fasted states. An opposite trend has been reported in cattle, sheep and chicken in which low RFI animals were hypothesized to be less susceptible to stress than high RFI animals (Herd and Arthur, 2009). Our results rather suggest that low RFI pigs would be more susceptible to stress but, in view of these highly controversial data, additional studies are warranted to investigate the relationships between stress susceptibility and RFI.

\section{Muscle Glycogen Content and Distribution}

According to our data, the absolute decrease in glycogen content during the first 30 min postmortem did not differ between RFI lines, in accordance with the absence of any line effect on $\mathrm{pH}$ at 30 min postmortem. 
In contrast, pigs from the low RFI line exhibited decreased ultimate $\mathrm{pH}$ and greater lightness in LM, SM, and BFM compared with pigs from the high RFI line, in agreement with previously reported genetic correlations from the same selection experiment (Gilbert et al., 2007). This is in accordance with data obtained in a large scale study involving Dutch Yorkshire pigs (de Vries et al., 1994) where reduced RFI was associated with decreased meat ultimate $\mathrm{pH}$ and increased lightness and drip loss. However, such effects were not found in a selection experiment built to reduce RFI in Yorkshire pigs (Cai et al., 2008; Fan et al., 2010) or in another study where reduction in RFI was achieved through selection for high growth rate under restricted feeding (Nguyen et al., 2004). The discrepancy between current results and those of Cai et al. (2008) might be due to differences in the equations used to calculate RFI, the genetic background of the pigs, preslaughter and slaughter conditions, and the fact that they only compared a low vs. a randomly selected RFI line. In the present study, in vivo LM glycogen content was greater in low RFI pigs, which likely explains the decreased LM ultimate $\mathrm{pH}$ of these pigs. Interestingly, we also observed a decreased ultimate $\mathrm{pH}$ in BFM, another glycolytic muscle, in the low RFI pigs. The greater LMC and in vivo muscle glycogen content in the low RFI line pigs are in agreement with the positive genetic correlation generally reported between lean-to-fat ratio and in vivo muscle glycogen content (Sellier, 1998; Larzul et al., 1999).

Because glycolytic IIBW fibers generally contain more glycogen than other fiber types at slaughter (Lefaucheur, 2010), the greater muscle glycogen content in LM of low RFI pigs may be related to their greater percentage of IIBW fibers. However, neither the percentage of IIBW fibers used as a covariate nor the $(\mathrm{RFI}$ line $\times$ covariate) interaction were significant (data not shown), suggesting that differences in the percentage of IIBW fibers between RFI lines did not explain differences in LM glycogen content. Moreover, in vivo glycogen content was not different between fiber types in the high RFI pigs in our study, likely because muscle biopsies were taken without any previous physical exercise, stress, or fasting. The differences in glycogen content usually reported between fiber types at slaughter have indeed been ascribed to be due to different preslaughter physical activity or stress or both, leading to a greater muscle glycogen decrease in oxidative compared with glycolytic fibers (Karlsson et al., 1994). Because pigs from both RFI lines were biopsied in similar conditions in the present experiment, most of the line divergence in glycogen content can be attributed to the divergent selection for RFI, and not to environmental factors, with a specific accumulation of glycogen in glycolytic IIBW fibers in low RFI pigs. Interestingly, a specific accumulation of glycogen in IIBW fibers has also been reported in pigs carrying the dominant AMPK $\gamma 3$ R225Q mutation (Marinova et al., 1992; Lebret et al., 1999). However, in contrast to low RFI animals,
AMPK $\gamma 3$ R225Q-mutated pigs exhibited decreased percentage and relative area of IIBW fibers in LM, less LDH activity, and greater CS and HAD activities, suggesting a greater reliance of glycolytic muscles on fatty acid oxidation. Therefore, muscle metabolic changes in AMPK $\gamma 3$ R225Q-mutated pigs resemble those seen when muscles adapt to an increased physical activity and are drastically different from those observed in low RFI pigs (i.e., an increased proportion of IIBW fibers in LM and a decreased HAD activity in LM, SM, and BFM), denoting a decreased reliance of glycolytic muscles on fatty acid oxidation. Beside the greater glycolytic potential in LM, SM, and BFM, low RFI pigs also exhibited reduced intramuscular fat content, suggesting a negative relationship between both traits. However, a direct functional relationship between intramuscular fat content and muscle glycogen stores or fiber type composition is unlikely and still highly controversial (Lefaucheur, 2010). Thus, the mechanisms underlying the increased glycogen content in glycolytic muscles of low RFI pigs and its specific accumulation in the IIBW fibers are unknown. Because of its strong implication in the regulation of glycogen and fat metabolism in skeletal muscle (Kahn et al., 2005), the AMPK pathway is an interesting candidate to better understand differences in muscle properties, and more generally in energy metabolism efficiency, between RFI lines.

\section{Muscle Metabolic and Contractile Properties}

Based on the HAD activity, our data suggest that high RFI pigs could potentially oxidize more fatty acids in mitochondria in glycolytic muscles, and that differences in mitochondrial activity could be involved to explain differences in energy metabolism efficiency between RFI lines. Mitochondria isolated from LM of low RFI steers have indeed been reported to have a greater degree of coupling, as assessed by RCR determination (Kolath et al., 2006a). Moreover, breast muscle mitochondria from broilers with high feed efficiency have been shown to exhibit a more tightly coupled respiratory chain along with decreased electron leak and reactive oxygen species production compared with broilers with low feed efficiency (Bottje et al., 2004). Improved efficiency of feed utilization could thus be related to a greater degree of mitochondrial coupling. However, our results obtained from a subset of animals from both lines did not show any significant line difference for the maximal rate of oxygen consumption and RCR. This discrepancy could be due to the limited sampling used in the present experiment but could also be ascribed to the biological material used to study mitochondrial respiration (i.e., permeabilized fibers in the present work vs. isolated mitochondria in other studies). Indeed, the cytoskeleton present in permeabilized fibers has been shown to play a key role in the regulation of mitochondrial respiration (Appaix et al., 2003). Consistently with the lack of line difference in coupling between electron transport chain and oxidative phosphorylation, we did 
not find any line difference in the amount of UCP2 and UCP3 mRNA in LM, in accordance with data reported for mRNA and protein UCP abundance in cattle LM (Kolath et al., 2006b). Finally, because protein turnover is also an energetically expensive process, a greater protein turnover in high RFI pigs could contribute to their decreased feed efficiency. Data supporting this hypothesis are the decreased myofibril fragmentation index and greater calpastatin content found in low vs. high RFI steers at slaughter, suggesting a decreased fractional protein degradation in the low RFI animals (McDonagh et al., 2001; Castro Bulle et al., 2007). This would be consistent with the greater percentage of IIBW fibers in our low RFI pigs because glycolytic fibers have been reported to exhibit a decreased protein turnover than oxidative fibers (Lewis et al., 1984).

Among the multiple sources of variation in RFI, physical activity is potentially an important one because of its large effect on muscle energy expenditure. Indeed, divergent selection for RFI in chicken and cattle, or for heat loss or food intake corrected for BW in mice, all show that less efficient lines are physically more active than more efficient ones (Luiting et al., 1991; Mousel et al., 2001; Herd and Arthur, 2009; Lancaster et al., 2009; Kelly et al., 2010). In pigs, high RFI animals have been shown to exhibit a greater total daily feeding time, a decreased rate of feed consumption, and a greater number of visits to a feeding station, denoting a greater feeding related physical activity (de Haer et al., 1993; Gilbert et al., 2009; Young et al., 2009). Therefore, high RFI pigs could be less efficient because of a greater physical activity. Due to the known positive effects of physical exercise on oxidative metabolism in skeletal muscle (Pette and Staron, 1997), high RFI pigs were expected to exhibit a greater muscle oxidative metabolism. This was confirmed by the decreased percentage and relative area of glycolytic IIBW fibers in LM, and the tendency for a greater HAD activity in LM, SM, and BFM of high RFI pigs, but this was not supported by the lack of line differences in CS activity. The relationships between physical activity and RFI, and underlying mechanisms, will have to be further studied on next generations of selection.

\section{Meat Quality Traits}

In pigs, increasing the proportion of IIBW fibers and myofiber CSA, or decreasing intramuscular fat content are associated with an impairment of some meat quality traits such as water-holding capacity, flavor, juiciness, and tenderness (Devol et al., 1988; Larzul et al., 1997; Fernandez et al., 1999; Rehfeldt et al., 2000). Moreover, increasing muscle glycolytic potential at slaughter can lead to a low ultimate $\mathrm{pH}$ and a decrease in water-holding capacity of fresh and cooked pork (Monin, 1988). Therefore, the greater proportion of IIBW fibers, myofiber CSA, and glycolytic potential, along with the decreased intramuscular fat content in LM of efficient low RFI pigs are likely to impair their meat quality, as suggested by their decreased ultimate $\mathrm{pH}$ and greater lightness and drip loss compared with the high RFI pigs. This is consistent with the unfavorable genetic correlations often reported between pork quality and feed conversion efficiency (Cameron et al., 1999; Hermesch et al., 2000; Lonergan et al., 2001; Hoque et al., 2009). Interestingly, de Vries et al. (1994) evoked a greater risk of DFD meat in high RFI pigs, in connection with their reduced muscle glycogen content at slaughter and greater ultimate $\mathrm{pH}$ of meat. Depending on preslaughter conditions, various meat quality defaults can arise and further work is needed to establish the relationships between RFI and pork quality under different preslaughter conditions, in particular regarding technological and sensory traits.

\section{Conclusions}

The current study indicates that pigs from the low RFI line when fed ad libitum exhibited similar growth rate but leaner carcasses and decreased intramuscular fat content compared with pigs from the high RFI line. The greater LMC of low RFI pigs was associated with hypertrophy of fast-twitch type II myofibers, a shift toward more glycolytic IIBW myofibers, those fibers containing $\mathrm{b}$, xb, or $\mathrm{x} \mathrm{MyHC}$, and greater muscle glycogen content specifically in IIBW fibers. This was associated with a decreased ultimate $\mathrm{pH}$, and greater lightness and drip loss in LM of low RFI pigs, suggesting that selection for reduced RFI may impair some meat quality traits. Because consumers and processing industry put increasing emphasis on the quality of pork, further work is needed to better evaluate the influence of RFI on technological and sensory quality of pig meat. Regarding muscle metabolic characteristics, pigs from the low RFI line tended to exhibit a decreased reliance of muscle energy metabolism on fatty acid $\beta$-oxidation in glycolytic muscles. However, a clear picture of the differences in muscle glycogen and lipid metabolism between RFI lines still deserves further investigation.

\section{LITERATURE CITED}

Appaix, F., A. V. Kuznetsov, Y. Usson, L. Kay, T. Andrienko, J. Olivares, T. Kaambre, P. Sikk, R. Margreiter, and V. Saks. 2003. Possible role of cytoskeleton in intracellular arrangement and regulation of mitochondria. Exp. Physiol. 88:175-190.

Barea, R., S. Dubois, H. Gilbert, P. Sellier, J. van Milgen, and J. Noblet. 2010. Energy utilization in pigs selected for high and low residual feed intake. J. Anim. Sci. 88:2062-2072.

Bordas, A., M. Tixier-Boichard, and P. Mérat. 1992. Direct and correlated responses to divergent selection for residual feed intake in Rhode Island Red laying hens. Br. Poult. Sci. 33:741-754.

Bottje, W. G., M. Iqbal, N. R. Pumford, C. Ojano-Dirain, and K. Lassiter. 2004. Role of mitochondria in the phenotypic expression of feed efficiency. J. Appl. Poult. Res. 13:94-105.

Bunter, K. L., W. Cai, D. J. Johnston, and J. C. M. Dekkers. 2010. Selection to reduce residual feed intake in pigs produces a correlated response in juvenile insulin-like growth factor-I concentration. J. Anim. Sci. 88:1973-1981.

Cai, W., D. S. Casey, and J. C. Dekkers. 2008. Selection response and genetic parameters for residual feed intake in Yorkshire swine. J. Anim. Sci. 86:287-298. 
Cameron, N. D., G. R. Nute, S. N. Brown, M. Enser, and J. D. Wood. 1999. Meat quality of Large White pig genotypes selected for components of efficient lean growth rate. Anim. Sci. 68:115-127.

Castro Bulle, F. C., P. V. Paulino, A. C. Sanches, and R. D. Sainz. 2007. Growth, carcass quality, and protein and energy metabolism in beef cattle with different growth potentials and residual feed intakes. J. Anim. Sci. 85:928-936.

Damon, M., I. Louveau, L. Lefaucheur, B. Lebret, A. Vincent, P. Leroy, M. P. Sanchez, P. Herpin, and F. Gondret. 2006. Number of intramuscular adipocytes and fatty acid binding protein 4 content are significant indicators of intramuscular fat level in crossbred Large White $\times$ Duroc pigs. J. Anim. Sci. 84:1083-1092.

Dauncey, M. J. 1990. Thyroid hormones and thermogenesis. Proc. Nutr. Soc. 49:203-215.

de Haer, L. M. C., P. Luiting, and H. L. M. Aarts. 1993. Relations among individual (residual) feed intake, growth performance and feed intake pattern of growing pigs in group housing. Livest. Prod. Sci. 36:233-253.

Devol, D. L., F. K. Mckeith, P. J. Bechtel, P. J. Novakofski, R. D. Shanks, and T. R. Carr. 1988. Variation in composition and palatability traits and relationships between muscle characteristics and palatability in a random sample of pork carcasses. J. Anim. Sci. 66:385-395.

de Vries, A. G., P. G. van der Wal, T. Long, G. Eikelenboom, and J. W. M. Merks. 1994. Genetic parameters of pork quality and production traits in Yorkshire populations. Livest. Prod. Sci. 40:277-289.

Fan, B., S. Lkhagvadorj, W. Cai, J. Young, R. M. Smith, J. C. M. Dekkers, E. Huff-Lonergan, S. M. Lonergan, and M. F. Rothschild. 2010. Identification of genetic markers associated with residual feed intake and meat quality traits in the pig. Meat Sci. 84:645-650.

Fernandez, X., L. Lefaucheur, and M. Candek-Potokar. 1995. Comparative study of two classifications of muscle fibres: Consequences for the photometric determination of glycogen according to fiber type in red and white muscle of the pig. Meat Sci. $41: 225-235$.

Fernandez, X., G. Monin, A. Talmant, J. Mourot, and B. Lebret. 1999. Influence of intramuscular fat content on the quality of pig meat - 1 . Composition of the lipid fraction and sensory characteristics of M. longissimus lumborum. Meat Sci. 53:59-65.

Florini, J. R., D. Z. Ewton, and S. A. Coolican. 1996. Growth hormone and the insulin-like growth factor system in myogenesis. Endocr. Rev. 17:481-517.

Fujii, J., K. Otsu, F. Zorzato, S. de Leon, V. K. Khanna, J. E. Weiler, P. J. O'Brien, and D. H. MacLennan. 1991. Identification of a mutation in porcine ryanodine receptor associated with malignant hyperthermia. Science 253:448-451.

Gabarrou, J. F., P. A. Geraert, J. Williams, L. Ruffier, and N. Rideau. 2000. Glucose-insulin relationships and thyroid status of cockerels selected for high or low residual food consumption. Br. J. Nutr. 83:645-651.

Geverink, N. A., M. A. W. Ruis, R. Eisen, E. Lambooij, H. J. Blokhuis, and V. M. Wiegant. 1999. The effect of shot biopsy on behavior, salivary cortisol, and heart rate in slaughter pigs. J. Anim. Sci. 77:1614-1619.

Gilbert, H., S. Al Aïn, J. P. Bidanel, H. Lagant, Y. Billon, P. Guillouet, J. Noblet, and P. Sellier. 2009. Sélection divergente sur la consommation alimentaire résiduelle du porc en croissance: Effets corrélatifs sur le comportement alimentaire. Journ. Rech. Porcine Fr. 41:31-32.

Gilbert, H., J. P. Bidanel, J. Gruand, J. C. Caritez, Y. Billon, P. Guillouet, H. Lagant, J. Noblet, and P. Sellier. 2007. Genetic parameters for residual feed intake in growing pigs, with emphasis on genetic relationships with carcass and meat quality traits. J. Anim. Sci. 85:3182-3188.

Gueguen, N., L. Lefaucheur, P. Ecolan, M. Fillault, and P. Herpin. 2005. $\mathrm{Ca}^{2+}$-activated myosin-ATPases, creatine and adenylate kinases regulate mitochondrial function according to myofibre type in rabbit. J. Physiol. 564:723-735.
Hamilton, D. N., M. Ellis, J. R. Hembree, F. K. Mckeith, K. D. Miller, and K. W. Purser. 2002. The impact of longissimus glycolytic potential and short-term feeding of magnesium sulfate heptahydrate prior to slaughter on carcass characteristics and pork quality. J. Anim. Sci. 80:1586-1592.

Henriksson, J. 1990. The possible role of skeletal muscle in the adaptation to periods of energy deficiency. Eur. J. Clin. Nutr. 44:55-64.

Herd, R. M., and P. F. Arthur. 2009. Physiological basis for residual feed intake. J. Anim. Sci. 87:E64-E71.

Hermesch, S., B. G. Luxford, and H. U. Graser. 2000. Genetic parameters for lean meat yield, meat quality, reproduction and feed efficiency traits for Australian pigs. 2. Genetic relationships between production, carcase and meat quality traits. Livest. Prod. Sci. 65:249-259.

Honikel, K. O. 1998. Reference methods for the assessment of physical characteristics of meat. Meat Sci. 49:447-457.

Hoque, M. A., K. Katoh, and K. Suzuki. 2009. Genetic associations of residual feed intake with serum insulin-like growth factor-I and leptin concentrations, meat quality, and carcass cross sectional fat area ratios in Duroc pigs. J. Anim. Sci. 87:3069-3075.

Hoque, M. A., K. Suzuki, H. Kadowaki, T. Shibata, and T. Oikawa. 2007. Genetic parameters for feed efficiency traits and their relationships with growth and carcass traits in Duroc pigs. J. Anim. Breed. Genet. 124:108-116.

Houseknecht, K. L., C. A. Baile, R. L. Matteri, and M. E. Spurlock. 1998. The biology of leptin: A review. J. Anim. Sci. 76:14051420 .

Johnson, Z. B., J. J. Chewning, and R. A. Nugent. 1999. Genetic parameters for production traits and measures of residual feed intake in Large White swine. J. Anim. Sci. 77:1679-1685.

Kahn, B. B., T. Alquier, D. Carling, and D. G. Hardie. 2005. AMPactivated protein kinase: Ancient energy gauge provides clues to modern understanding of metabolism. Cell Metab. 1:15-25.

Karlsson, A., B. Essén-Gustavsson, and K. Lundström. 1994. Muscle glycogen depletion pattern in halothane-gene-free pigs at slaughter and its relation to meat quality. Meat Sci. 38:91-101.

Kelly, A. K., M. Mcgee, D. H. Crews, A. G. Fahey, A. R. Wylie, and D. A. Kenny. 2010. Effect of divergence in residual feed intake on feeding behavior, blood metabolic variables, and body composition traits in growing beef heifers. J. Anim. Sci. $88: 109-123$

Kennedy, B. W., J. H. van der Werf, and T. H. Meuwissen. 1993. Genetic and statistical properties of residual feed intake. J. Anim. Sci. 71:3239-3250.

Kolath, W. H., M. S. Kerley, J. W. Golden, and D. H. Keisler. 2006a. The relationships between mitochondrial function and residual feed intake in Angus steers. J. Anim. Sci. 84:861-865.

Kolath, W. H., M. S. Kerley, J. W. Golden, S. A. Shahid, and G. S. Johnson. 2006b. The relationships among mitochondrial uncoupling protein 2 and 3 expression, mitochondrial deoxyribonucleic acid single nucleotide polymorphisms, and residual feed intake in Angus steers. J. Anim. Sci. 84:1761-1766.

Labroue, F., R. Guéblez, P. Sellier, and M. C. Meunier-Salaün. 1994. Feeding behavior of group-housed Large White and Landrace pigs in French central test stations. Livest. Prod. Sci. 40:303312 .

Lancaster, P. A., G. E. Carstens, F. R. Ribeiro, L. O. Tedeschi, and D. H. Crews. 2009. Characterization of feed efficiency traits and relationships with feeding behavior and ultrasound carcass traits in growing bulls. J. Anim. Sci. 87:1528-1539.

Larzul, C., L. Lefaucheur, P. Ecolan, J. Gogué, A. Talmant, P. Sellier, P. Le Roy, and G. Monin. 1997. Phenotypic and genetic parameters for longissimus muscle fiber characteristics in relation to growth, carcass, and meat quality traits in Large White pigs. J. Anim. Sci. 75:3126-3137.

Larzul, C., P. Le Roy, J. Gogué, A. Talmant, B. Jacquet, L. Lefaucheur, P. Ecolan, P. Sellier, and G. Monin. 1999. Selection for reduced muscle glycolytic potential in Large White pigs. II. Correlated responses in meat quality and muscle compositional traits. Genet. Sel. Evol. 31:61-76. 
Lebret, B., P. Le Roy, G. Monin, L. Lefaucheur, J. C. Caritez, A. Talmant, J. M. Elsen, and P. Sellier. 1999. Influence of the three RN genotypes on chemical composition, enzyme activities and myofiber characteristics of porcine skeletal muscle. J. Anim. Sci. 77:1482-1489.

Lebret, B., M. C. Meunier-Salaün, A. Foury, P. Mormède, E. Dransfield, and J. Y. Dourmad. 2006. Influence of rearing conditions on performance, behavioral, and physiological responses of pigs to preslaughter handling, carcass traits, and meat quality. J. Anim. Sci. 84:2436-2447.

Lefaucheur, L. 2010. A second look into fibre typing-Relation to meat quality. Meat Sci. 84:257-270.

Lefaucheur, L., D. Milan, P. Ecolan, and C. Le Callennec. 2004. Myosin heavy chain composition of different skeletal muscles in Large White and Meishan pigs. J. Anim. Sci. 82:1931-1941.

Lewis, S. E., F. J. Kelly, and D. F. Goldspink. 1984. Pre- and postnatal growth and protein turnover in smooth muscle, heart and slow- and fast-twitch skeletal muscles of the rat. Biochem. J. 217:517-526.

Lkhagvadorj, S., L. Qu, W. Cai, O. P. Couture, C. R. Barb, G. J. Hausman, D. Nettleton, L. L. Anderson, J. C. M. Dekkers, and C. K. Tuggle. 2010. Gene expression profiling of the short-term adaptive response to acute caloric restriction in liver and adipose tissues of pigs differing in feed efficiency. Am. J. Physiol. Regul. Integr. Comp. Physiol. 298:R494-R507.

Lonergan, S. M., E. Huff-Lonergan, L. J. Rowe, D. L. Kuhlers, and S. B. Jungst. 2001. Selection for lean growth efficiency in Duroc pigs influences pork quality. J. Anim. Sci. 79:2075-2085.

Louveau, I., and M. Bonneau. 1996. Effect of a growth hormone infusion on plasma insulin-like growth factor-I in Meishan and Large White pigs. Reprod. Nutr. Dev. 36:301-310.

Luiting, P., J. W. Schrama, W. van Der Hel, and E. M. Urff. 1991. Metabolic differences between white Leghorns selected for high and low residual feed consumption. Br. Poult. Sci. 32:763782.

Marinova, P., L. Lefaucheur, X. Fernandez, and G. Monin. 1992. Relationship between metabolism and glycogen content in skeletal muscle fibers of Large White and Hampshire crossbred pigs. J. Muscle Foods 3:91-97.

McDonagh, M. D., R. M. Herd, E. C. Richardson, V. H. Oddy, J. A. Archer, and P. F. Arthur. 2001. Meat quality and the calpain of feedlot steers following a single generation of divergent selection for residual feed intake. Aust. J. Exp. Agric. 41:1013-1021.

Métayer, A., and G. Daumas. 1998. Estimation, par découpe, de la teneur en viande maigre des carcasses de porcs. Journ. Rech. Porcine Fr. 30:3-26.

Milan, D., J. T. Jeon, V. Amarger, A. Robic, M. Thelander, C. Rogel-Gaillard, S. Paul, N. Iannuccelli, L. Rask, H. Ronne, K. Lundstrom, N. Reinsch, J. Gellin, E. Kalm, P. Le Roy, P. Chardon, and L. Andersson. 2000. A mutation in PRKAG3 associated with excess glycogen content in pig skeletal muscle. Science 288:1248-1251.

Monin, G. 1988. Evolution post-mortem du tissu musculaire et conséquences sur les qualités de la viande de porc. Journ. Rech. Porcine Fr. 20:201-214.
Mousel, M. R., W. W. Stroup, and M. K. Nielsen. 2001. Locomotor activity, core body temperature, and circadian rhythms in mice selected for high or low heat loss. J. Anim. Sci. 79:861-868.

Mrode, R. A., and B. W. Kennedy. 1993. Genetic variation in measures of food efficiency in pigs and their genetic relationships with growth rate and backfat. Anim. Prod. 56:225-232.

Nguyen, N. H., C. P. McPhee, and C. M. Wade. 2004. Genetic selection strategies for efficient lean growth in pigs. Pig News Inf. $25: 149 \mathrm{~N}-163 \mathrm{~N}$

Nguyen, N. H., C. P. McPhee, and C. M. Wade. 2005. Responses in residual feed intake in lines of Large White pigs selected for growth rate on restricted feeding (measured on ad libitum individual feeding). J. Anim. Breed. Genet. 122:264-270.

Nkrumah, J. D., D. H. Keisler, D. H. Crews, J. A. Basarab, Z. Wang, C. Li, M. A. Price, E. K. Okine, and S. S. Moore. 2007. Genetic and phenotypic relationships of serum leptin concentration with performance, efficiency of gain, and carcass merit of feedlot cattle. J. Anim. Sci. 85:2147-2155.

Patterson, H. D., and R. Thompson. 1971. Recovery of inter-block information when block sizes are unequal. Biometrika 58:545554.

Pearse, A. G. E. 1968. Histochemistry: Theoretical and Applied. Little, Brown and Co., Boston, MA.

Pette, D., and R. S. Staron. 1997. Mammalian skeletal muscle fiber type transitions. Int. Rev. Cytol. 170:143-223.

Qian, H., C. R. Barb, M. M. Compton, G. J. Hausman, M. J. Azain, R. R. Kraeling, and C. A. Baile. 1999. Leptin mRNA expression and serum leptin concentrations as influenced by age, weight, and estradiol in pigs. Domest. Anim. Endocrinol. 16:135-143.

Rehfeldt, C., I. Fiedler, G. Dietl, and K. Ender. 2000. Myogenesis and postnatal skeletal muscle cell growth as influenced by selection. Livest. Prod. Sci. 66:177-188.

Richardson, E. C., R. M. Herd, J. A. Archer, and P. F. Arthur. 2004. Metabolic differences in Angus steers divergently selected for residual feed intake. Aust. J. Exp. Agric. 44:441-452.

Sellier, P. 1998. Genetics of meat and carcass traits. Pages 463-510 in The Genetics of the Pig. M. F. Rothschild and A. Ruvinsky, ed. CAB Int., Wallingford, UK.

Suzuki, K., K. Inomata, K. Katoh, H. Kadowaki, and T. Shibata. 2009. Genetic correlations among carcass cross-sectional fat area ratios, production traits, intramuscular fat, and serum leptin concentration in Duroc pigs. J. Anim. Sci. 87:2209-2215.

Suzuki, K., M. Nakagawa, K. Katoh, H. Kadowaki, T. Shibata, H. Uchida, Y. Obara, and A. Nishida. 2004. Genetic correlation between serum insulin-like growth factor-1 concentration and performance and meat quality traits in Duroc pigs. J. Anim. Sci. 82:994-999

Wigmore, P. M., and N. C. Stickland. 1983. Muscle development in large and small pig fetuses. J. Anat. 137:235-245.

Young, J. M., W. Cai, and J. C. M. Dekkers. 2009. Effect of selection for residual feed intake on feeding behavior in pigs. J. Anim. Sci. 87(E-Suppl. 2):355-356. 
References

Citations

This article cites 70 articles, 34 of which you can access for free at: http://www.journalofanimalscience.org/content/89/4/996\#BIBL

This article has been cited by 8 HighWire-hosted articles:

http://www.journalofanimalscience.org/content/89/4/996\#otherarticles 